Running Head: PROFILES OF CHANGE: PATTERNS AND DYNAMICS

\title{
Profiles of change: Patterns and dynamics and change coordination during a specialized educational program for professionals working with multi-challenged families
}

\author{
Ana Teixeira de Melo $^{1} \&$ Madalena Alarcão ${ }^{1}$ \\ ${ }^{1}$ Centre for Social Studies, University of Coimbra, Faculty of Psychology and Education Sciences of the University \\ of Coimbra.
}

Corresponding author:

Ana Teixeira de Melo

Address: Apartado 2001, EC Praia da Granja, 4411-901 São Félix da Marinha, Portugal.

E-mail: anamelopsi@gmail.com

Biosketch:

Ana Teixeira de Melo is a post-doctoral research fellow at the Centre for Social Sciences and the Faculty of Psychology and Education Sciences of the University of Coimbra, with a fellowship from the Foundation for Science and Technology (SFRH/BPD/77781/2011).

Madalena Alarcão is Associate Professor at the Faculty of Psychology and Education Sciences of the University of Coimbra. She is a family therapist and a supervisor member of the Portuguese Society of Family Therapy. 


\begin{abstract}
This paper describes an exploratory, discovery-oriented study, aimed at inspecting the structure and dynamics of emotional, behavioural and cognitive changes, as well as the coordination of these changes, by professionals participating in a specialized educational/training program. The program aimed at the implementation of a family assessment and intervention model for multichallenged families with at-risk, maltreated of neglected children. The authors combined a metaphorical approach to complexity and dynamic systems' theories, through the heuristic use of its core concepts, with grounded methods for qualitative analysis, in order to create a coding framework applicable to data collected from simple self-report measures of change. This coding schemed showed potential to illuminate individual processes of change and for application in other fields. This scheme was used with data collected throughout the 42 weeks duration of the program. The results, after binary conversion of the variables, were subjected to a hierarchical cluster analysis, in order to identify profiles of change. We obtained a final solution of 6 clusters, aggregating different properties of change and different evolution dynamics of the trajectories of change and change coordination. Implications for educational practice and for future studies are discussed.
\end{abstract}

Keywords: dynamical systems; coordination dynamics; change processes; professional development; trajectories of change 


\section{Profiles of change: Patterns and dynamics and change coordination during a specialized educational program for professionals working with multi-challenged families}

Many social scientists, and psychologists in particular, have subscribed to a view of human systems as complex and dynamical (Guastello, Koopmans, \& Pincus, 2009; Hollenstein, 2011; Lewis, 2000). Change is, by definition, a dynamical concept and many authors recognize both development and learning as complex, nonlinear, self-organizing phenomena (Fogel, 2011; Stamovlasis \& Koopmans, 2014; Thelen \& Smith, 2006; Van Geert, 2011).

Nevertheless some contributions (Graesser, \& D’Mello, 2012; Stamovlasis \& Koopmans, 2014) there are still few studies exploring the complexities and the dynamics of change processes in educational settings, namely adult education (Wettstein, \& Thommen, 2009).

In family therapy, the subject of change is paramount. Besides teaching technical skills systemic family therapy training programs dedicate special attention to the personal development of the professional (Elkaïm, 1988). Participating in such programs can be a transforming experience (Nel, 2006), but this has not been studied in dynamic terms. Systemic family interventions extend to community contexts where multichallenged families appear as some of the most difficult families, especially in cases of child protection. These cases call for complex professional skills (Sharlin \& Shamai, 2000).

We have previously described process and outcome evaluations of a specialized educational/training program for professionals working in multidisciplinary community-based teams, to support multi-challenged families with at-risk, abused or neglected children ("Authors", 2013a). This program aims at promoting skills to plan and conduct (multi)systemic, collaborative and strength-based assessments and interventions, based in a conceptualization of the family as a complex dynamical system ("Authors", 2013a;2013b]. Additionally, it aims to promote the professionals' emotional and psychological development.

The evaluations revealed some unexpected results. For the majority of the participants, the program's rationale was almost opposite to their habitual practice (mostly based on individual-focused, linear causality, non-systemic, deficit-based, expert-driven models). By the end of the training, participants' behavioural skills had improved but were only at minimal levels and still unstable. Case-conceptualization skills were also fragile despite the participants' report of significant changes in their way of thinking. There were reports of profound emotional changes, which, for some participants was particularly disturbing. We raised the hypothesis that high levels of emotional change could have impaired the cognitive and behavioural changes and that the stability of the behavioural changes could relate to fragile cognitive changes.

The present study focuses the processes of change of professionals participating in an improved version of the above-mentioned program. We conceptualized each participant, as well the emotional, behavioural and cognitive domains, as complex dynamical systems. We assumed that the participation in the program pulls the participants out of their habitual equilibrium. Among other factors, the reorganization of each domain of change probably depends on the coordination between them.

In this study, we wished to explore the processes and dynamics within and between domains of change. We wanted to understand the processes of learning and changing for the "average" participant, in order to derive general implications, but we also wanted to understand deviations and to identify particular aspects to which a program facilitator should be attentive to.

Complexity and, particularly, dynamic systems theories, offered us a vocabulary to think 
in dynamic terms and different methods (Granic \& Hollenstein, 2003; Van Geert, 2012). However, our exploratory purposes required a concrete operational language with qualitative descriptive capacity to capture, from graphical representations of the evolution of relevant variables through time, the specificities of the participants' trajectories of change regarding its structural (contents/patterns) and dynamical features. We also aspired to develop a qualitative coding framework with potential to be content independent, which could be used in other studies using ordinary social sciences' data collection methods.

In sum, in the present study, we aimed to answer the questions: a) how do the participants in an educational program such as ("model's name, "Authors", 2011) change, and how are different dimensions of change (emotional, behavioural, cognitive) coordinated?, b) is it possible to identify different profiles of change?, c) is it possible to develop a qualitative coding system to code longitudinal self-reported data in order to rigorously describe the structural and dynamical aspects of change and change coordination? and, d) what categories and which properties best describe the structural and dynamical features of the learning/changing process and differentiate different profiles of change?

\section{Participants}

\section{Method}

Fifteen professionals ( 5 psychologists, 6 social workers and 4 social educators), from 6 teams, working in specialized family support and parental counselling centres in Portugal, participated in this study. Three participants, belonging to the same team, terminated their participation at about two thirds of the length of the program, due to insufficient fulfilment of each component and organizational issues. Only data from the 12 participants who concluded the program were used in the analysis of individual trajectories.

Despite the inexistence of an Institutional Review Boards in Portugal, the authors' Faculty Scientific Committee approved the research project encompassing this study. We also obtained informed consent from all participants.

\section{The program}

The professionals participated in an integrated and specialized education program aimed at preparing them to implement a family-centered, integrative approach to assess and support multichallenged families with at-risk, abused or neglected children in their process of change. That approach embraces a (multi)systemic, ecologic, collaborative and a strength-based orientation ("name of approach", "Authors, 2011). The program has two stages: an initial training period, approximately 11 months/11 modules long (42 weeks), and 9 to 12 month of supervised practice. Only the initial training is included in this study.

The program was improved to incorporate results of previous evaluations, and expanded from 9 to 11 months. In the earlier editions, critical periods of stress and change were identified around modules 4-5 and 6-7. For this study, the contents of these modules were divided with two additional ones. Each module length was approximately 4 weeks and contained several components. The last module is shorter (1 week) aiming at the integration of experiences. Each module comprehends the reading of a section of ("model's name", "Authors", 2011) a manual followed by a group training session, of approximately 6 hours, with practical exercises for the application of theoretical contents. In each module, the professionals collect and transcribe a video or audio recording of a session. The participants' performance in the sessions are assessed using standardized instruments ("Authors", 2012). Additionally, a monthly meeting is held with each team. The first part of the meeting is dedicated to case and theory-application discussions and to the assessment of the transcribed session. A second part concerns individual meetings 
with each participant regarding their autonomous exercises and performance. For this, each participant realizes two written exercises: a) a personal reflection exercise focused on themes of personal, professional and their own family functioning and development, b) an assessment exercise for the application of theory and case planning and conceptualization skills. The first author was the program facilitator.

\section{Data collection procedures}

Procedure. For this study, we collected the data weekly, during the 42 weeks of the training, through which the participants received a web-link to fill an electronic form. The participants' were involved in more extensive data collection procedures than described here, for other research purposes.

Measures. The electronic form contained 31 questions, regarding the participants' experiences with the program and self-perceived changes. It contained open and closed fields. A section with closed-questions asked the participants to rate the frequency and magnitude of the changes experienced during the week, in the emotional ("to what extent do you think you experienced emotions different from those you usually experience?" "To what extent was those emotions' intensity different than usual?"), behavioural ("To what extent did you behave differently than usual, showing new or non-habitual behaviours?"; "To what extent were those behaviours different than usual?") and the cognitive domains, regarding the form of thinking ("To what extent did you experience new or different ways of thinking about things?", "To what extent were those alternative ways of thinking different than usual?"). Other questions regarding changes in cognitive content are not included in this study. The response Likert scale ranged from 1 ("not at all frequent/ not at all different") to 5 ("very frequently/ totally different").

\section{Data analysis procedures}

Construction of a coding scheme. For the elaboration of a coding scheme, Complexity's and Dynamic Systems Theories' concepts such as state-spaces, attractors, transitions, bifurcations, fluctuations, self-organization, coordination dynamics were used heuristically, in a preliminary exploration of the data. These concepts also informed some transformations of the original data, as reported below. We wanted to avoid imposing a framework that did not fit the data or forcing it into pre-existing theory. Therefore, while keeping those concepts in the background, we approached the data with a bottom-up, inductive and discovery-oriented stance. We explored it relying on the contribution of techniques from grounded theory, namely open coding and axial coding and by making constant comparisons within and between codes and subjects (Charmaz, 2006; Strauss, 1987). Since we had no opportunity for theoretical sampling (Glaser \& Strauss, 2008) we filled in the unsaturated categories with properties that seemed theoretically plausible and resulted from a combination of the properties already observed in our sample. This is why, for some categories, there are properties that do not appear in our results. For example, although no participant in our sample showed a continuous pattern of change it was considered as a possibility. Therefore, we kept it as a feasible code (Appendix A). Future studies should continue to assess the adequacy of such properties.

We constructed the coding scheme through an in-depth analysis of the data produced during the first 27 weeks of the program. It was later refined during a thorough analysis of the entire 42-weeks period. In this latter stage, we used an inverse process by applying the codes to the data, in a top-down approach. This allowed us to test, once again, the fitness and adequacy of the codes, and allowed us to make some refinements in their operational definition. Some of the codes are truly emergent but others have a more constrained character, since they result from constraints imposed by our methodological choices or an arbitrary choice of cutting values. For 
example, we arbitrarily defined three levels of change and fixed a relative proportional value between variables to define pattern variables or attractors, as exemplified ahead.

Coding of the participants' trajectories. Different transformations of the data aimed at exploring different aspects of the change and coordination processes. Emotional changes (EC), behavioural changes (BC) and cognitive changes (CC) were computed with the sum of the frequency and magnitude ratings, into a composite variable, ranging from 2 to 10 . We used the percentiles 10 and 80 as cutting points for different levels of change. Values below percentile 10 were recoded as 0 (Low), and those above percentile 80 as 2 (High). All the other values were recoded as 1 (Moderate).

We created different graphical representation, for the 42 weeks, with the recoded values, to visualize the evolution of the changes. We also used auxiliary coding grids to count isolated fluctuations and stability and their size/level from week 1 to 42 . These grids were used to identify the patterns fluctuations and stability of each dimension of change, and the overall pattern of change processes. They allowed the systematic identification of the duration, size, and sequencing of the periods of fluctuations and stability, as well as their relationship.

We assessed coordination (the degree of concordance) by pairing the levels of change for each dimension. We created three variables representing Emotional-Behavioural Coordination (EBC), Emotional-Cognitive Coordination (ECC) and Cognitive-Behavioural Coordination (CBB). When the dimensions expressed the same level of change, the coordination variables were coded with values of 2, for Absolute coordination (AC). Relative coordination (RC) was coded with 1, representing instances of moderate change in one dimension and high in the other. Finally, when one of the dimensions expressed low levels of change, the variables was coded as 0 , standing for incoordination (IC).

The combination of the possible values for each pair of coordination generates three coordination states spaces with 9 possible states. We coded transversal coordination as present (1) when the level of change was the same for the three dimensions of change at a given time point and absent (0) when they differed.

With the Gridware software (Lamey, Hollenstein, Lewis, \& Granica, 2004) we obtained graphical representations for each of the participants' trajectories in the three coordination state spaces and for the entire sample. We repeated the procedures separately for each of five different periods of the program (each containing 2 modules/8 weeks, and the fifth adding an extra week for module 11).

We retrieved the following measures for each state/region: the mean number of events (discrete events in the region), the mean number of visits (a visit corresponds to one or more consecutive events in the same region, or state, beginning with an entry in that state and ending with its exit) and the proportional density (the mean percentage of events occurring in a given region/state in relation to the total number of events). By event we mean one data collection time point, or one week. The mean number of visits corresponds to the mean number of discrete visits of the trajectory to any other region/state outside the one of interest, before returning to it. The number of return visits is calculated and averaged across trajectories. A return is the sequence of events outside that region beginning with an exit and ending with a re-entry. We used these variables to identify primary and secondary attractor. States/regions with the lower mean value of return visits and proportional densities above $20 \%$ were considered as primary attractors. Those with the next lower mean return visits and densities between $15 \%$ and $20 \%$ were selected as secondary attractors. We selected a maximum of 2 primary attractors when there were two states with the same highest proportional densities and the same value of mean return visits. The 
same criteria was used to select 2 secondary attractors. In latter analyses, we reduced these 4 attractors to two main attractors: attractor 1(one the primary attractors) and attractor 2 (the second primary attractor or the first of the secondary attractors).

For each entire coordination state space we retrieved values of Dispersion (total number of cells visited) and Fluctuations (number of transitions between cells). Gridware computes the sum of the squared proportional durations across all cells, corrected for the number of cells and inverted in order to result in a value between 0 (no dispersion) and 1 (maximum dispersion). Changes in the attractors throughout each of the five periods of the training provided us with information regarding the dynamics of the coordination of changes.

We used the coding scheme previously developed to identify the properties of the trajectories of change and change coordination for the each participant.

\section{Results}

\section{Overall logic of the coding scheme and core categories}

The development of a coding scheme resulted in a series of categories, sub-categories and properties listed in Appendix A. Due to space limitations we do not detail here all operational definitions, which may be obtained from the authors, but we briefly describe some of the core categories and properties. Since the variables assessed are already reports of change, a trajectory of change is, in fact, the change of change, a sort of derivate of change or process.

Core categories are essentially of two types. On the one hand, there are elementary components or bedrock properties of the trajectories. On the other, there are pattern variables, built from the aggregation of these properties. The pattern categories are generally defined by the relative proportion and/or sequencing of the elementary properties. For example, the pattern of fluctuations is defined according to the relative proportion of a give type compared to others. Patterns of organization rely on the identification of the dominance or predominance of some elementary property. Patterns of dominance mean that only one type of elementary property is present while patterns of predominance mean that one (or two) patterns show a relative frequency at least $20 \%$ superior to others. When there are only two types of elements and they differ from less than $20 \%$ then the pattern is classified as a mixed pattern of dominance of $X$ and $Y$. When a third of more patterns differ from these, above $20 \%$, then the pattern is of predominance of $X$ and $Y$ with secondary patterns. When there are more than two elementary properties in the same circumstances then we code a mixed pattern without predominance. The same criteria applies for the corresponding trajectories of coordination.

We will briefly define the core categories and some of its most relevant properties.

Change expressivity corresponds to the intensity of the changes, measured by the proportion of the levels of change, throughout the trajectory. Patterns of change continuity represent the extent to which some level of change (moderate or high) is maintained throughout the trajectory. Quasi-continuous patterns have punctuations of low change events below $20 \%$ of the total events. In intermittent patterns, low events overcome $20 \%$ of the total number of events and are interspersed with moderate or high change events. The patterns of distributions of change classify the organization of the changes (moderate or high) in time, combining duration and organization. The classification of patterns of dominance and predominance applies as above described. The patterns of process of change represent the relationship (relative frequency and distribution) between the patterns of fluctuations and stability. Balanced trajectories may be intermittent or sequential. In the latter, long of very long periods of fluctuations and stability are intersperse. Both these trajectories have a dominant or predominant type of fluctuations or stability. Balanced diverse patterns show many forms of fluctuations and stability. The 
trajectories end in stability or end in fluctuations when there is very long block final period (five or more consecutive events). Fluctuant patterns have predominance of fluctuation over stability, with punctuations of short (three consecutive events) or long (to four consecutive events) periods of stability or frequent short periods of stability. Other patterns represent different balances, but we do not detail them here, since they do not appear in our results.

Main attractors (structure) and their dynamics characterize each coordination trajectory. From the beginning to the end (through the five periods of the program) there may be maintenance of primary attractors or change. New attractors may appear or there may be variation with a final return to earlier attractors. Additionally, the number of attractors may change and the primary attractors may evolve in different ways. A trajectory can maintain a single attractor, evolve to multistability (from a single to multiple attractors) or vice-versa (from multiple to a single attractor). Some cases show variations in the number of attractors, ending in single or multiple attractors. Ending tendencies apply when there is maintenance of a pattern for, at least, the two last periods of the training. Additionally, to code a final tendency of coordination there must be a clear decrease of fluctuations and dispersion.

\section{Profiles of change trajectories and dynamics of the coordination of changes \\ Trajectory of change for the whole sample. We analysed differences between the} distributions of the three types of changes, measured by the composite variable, of frequency and magnitude, at the level of the whole sample. A Friedman test revealed statistically significant differences $\left(\chi^{2}(2)=26.37, p=.000\right)$. Post-hoc Wilcoxon tests, with Bonferroni corrections, showed that emotional changes $(M=6.33 ; M d=6.00, S D=1.83)$ were superior to behavioural changes $M=6.06 ; M d=6.00, S D=1.81)(z=-4.38, p=.000)$ and that cognitive changes $(M=$ $6.39 ; M d=6.00, S D=1.67)$ were superior to behavioural changes $(z=-5.41, p=.000)$, but no difference existed between emotional and cognitive changes $(z=-1.74, p=081)$.

Kruskall-Wallis tests revealed no statistically significant differences between the five periods of trainings $\left(\mathrm{EC}, \chi^{2}(4)=5.41, p=.248 ; \mathrm{BC}, \chi^{2}(4)=4.89, p=.298 ; \mathrm{CC}, \chi^{2}(4)=2.88, p\right.$ $=.577)$. Emotional changes were correlated to behavioural $\left(r_{s p}=.67, \mathrm{p}=.000\right)$ and cognitive changes $\left(r_{s p}=.48, \mathrm{p}=.000\right)$, as well as behavioural and cognitive changes $\left(r_{s p}=.59, \mathrm{p}=.000\right)$.

From hereafter, we report results using all 9 states of change, composing a total of 1734 events (102 Low EC, 126 Low BC, 83 Low CC; 231 Moderate EC, 243 Moderate BC, 237 Moderate CC; 229 High EC, 193 High BC, 242 High CC). A Pearson Chi-Square test revealed a significant, although weak, association between type of change and level of change $\left(\chi^{2}(6)=\right.$ $15.08, p=.020 ; \Phi=.09)$. The percentages of events in each level were compared, for each domain of change, across five periods of the training. We used percentages instead of raw values to compensate for some missing values. Kruskal Wallis tests revealed no significant differences $\left(\right.$ Low EC $: \chi^{2}(4)=3.43, p=.489$; Low BC: $\chi^{2}(4)=4.21, p=.377$; Low CC: $\chi^{2}(4)=6.95, p=$ .139; Moderate EC: $\chi^{2}(4)=3.23, p=.520$; Moderate $\mathrm{BC}: \chi^{2}(4)=2.17, p=.705$; Moderate CC: $\chi^{2}(4)=8.42, p=.078$; High EC: $\chi^{2}(4)=3.41, p=.49$; High $\mathrm{BC}: \chi^{2}(4)=.96, p=.91$; High CC: $\left.\chi^{2}(4)=1.97, p=.741\right)$.

Coordination of changes at the level of the whole sample. We calculated the percentage of absolute coordination events for each type of coordination and used a Fridman test to compare them. We found statistically significant differences between the three types of coordination $\left(\chi^{2}(2)=19.29, p=.000\right)$. Post-hoc Wilcoxon tests, with Bonferroni corrections, revealed statistically significant differences between ECC $(M=59.08, S D=13.80$, Min $=33.33$, $\operatorname{Max}=90.9)$ and $\mathrm{EBC}(M=69.32, S D=11.63, \operatorname{Min}=44.44, \operatorname{Max}=100)(z=-4.09, p=.000)$ as 
well as between ECC and BCC $(M=67.89, S D=12.00$, Min $=44.44$, Max $=100)(z=-3.65, p$ $=.000$ ) coordination but not between $\mathrm{BCC}$ and $\mathrm{EBC}$.

Table 1 represents the averaged properties of the 15 trajectories considering each state in the three coordination spaces.

Table 1.

Distribution of coordination states for the averaged trajectories of all participants in the coordination state spaces

\begin{tabular}{|c|c|c|c|c|c|}
\hline State space & States & $\begin{array}{c}\text { Mean number } \\
\text { of events }\end{array}$ & $\begin{array}{c}\text { Mean number } \\
\text { of visits }\end{array}$ & $\begin{array}{l}\text { Mean return } \\
\text { visits }\end{array}$ & $\begin{array}{r}\text { Proportional } \\
\text { density }(\%)\end{array}$ \\
\hline \multirow{9}{*}{$\begin{array}{c}\text { Emotional- } \\
\text { Behavioural } \\
\text { coordination } \\
\quad(\mathrm{EBC})\end{array}$} & $\mathrm{E}(0) \times \mathrm{B}(0)$ & 5.67 & 4.6 & 4.95 & $13.5 \%$ \\
\hline & $\mathrm{E}(1) \times \mathrm{B}(1)^{\mathrm{a})}$ & 15.07 & 8.6 & 2.1 & $35.88 \%$ \\
\hline & $\mathrm{E}(2) \mathrm{X} B(2)$ & 5.6 & 3.87 & 4.86 & $13.33 \%$ \\
\hline & $\mathrm{E}(1) \mathrm{X} B(0)$ & 2.2 & 1.93 & 7.26 & $5.23 \%$ \\
\hline & $\mathrm{E}(2) X \mathrm{~B}(0)$ & 0.4 & 0.33 & - & $3.33 \%$ \\
\hline & $\mathrm{E}(0) \times \mathrm{B}(1)$ & 2.67 & 2.07 & 7.57 & $6.35 \%$ \\
\hline & $\mathrm{E}(0) \mathrm{X} B(2)$ & 0.4 & 0.4 & & $0.95 \%$ \\
\hline & $\mathrm{E}(1) \times \mathrm{B}(2)^{\mathrm{a})}$ & 15.07 & 8.6 & 2.1 & $35.88 \%$ \\
\hline & $\mathrm{E}(2) \times \mathrm{B}(1)$ & 1.53 & 1.47 & 8.5 & $3.64 \%$ \\
\hline \multirow{9}{*}{$\begin{array}{l}\text { Emotional- } \\
\text { cognitive } \\
\text { coordination } \\
(\text { ECC) }\end{array}$} & $\mathrm{E}(0) \times \mathrm{C}(0)$ & 4.2 & 3.6 & 6.04 & $10 \%$ \\
\hline & $E(1) \times C(1)^{a)}$ & 13.8 & 7.93 & 2.19 & $32.85 \%$ \\
\hline & $\mathrm{E}(2) \times \mathrm{C}(2)$ & 5.47 & 3.6 & 3.78 & $13.02 \%$ \\
\hline & $\mathrm{E}(1) \times \mathrm{C}(0)$ & 1.67 & 1.67 & 11 & $3.97 \%$ \\
\hline & $\mathrm{E}(2) X \mathrm{C}(0)$ & 0.53 & 0.53 & 10 & $1.26 \%$ \\
\hline & $\mathrm{E}(0) \times \mathrm{C}(1)$ & 3.53 & 3.53 & 5.99 & $8.40 \%$ \\
\hline & $\mathrm{E}(0) \times \mathrm{C}(2)$ & 0.6 & 0.6 & 6.75 & $14.28 \%$ \\
\hline & $E(1) \times C(2)^{b)}$ & 7.2 & 5.47 & 4.26 & $17.14 \%$ \\
\hline & $\mathrm{E}(2) \times \mathrm{C}(1)$ & 1.53 & 1.4 & 6.12 & $3.64 \%$ \\
\hline \multirow{9}{*}{$\begin{array}{l}\text { Behavioral- } \\
\text { cognitive } \\
\text { coordination } \\
\text { (BCC) }\end{array}$} & $\mathrm{B}(0) \mathrm{X} C(0)$ & 4.4 & 3.67 & 6.48 & $10.48 \%$ \\
\hline & $\mathrm{B}(1) \times \mathrm{C}(1)^{\mathrm{a})}$ & 13 & 7.67 & 2.61 & $30.95 \%$ \\
\hline & $\mathrm{B}(2) \mathrm{X} C(2)$ & 8.2 & 5.6 & 3.57 & $19.52 \%$ \\
\hline & $\mathrm{B}(0) \times \mathrm{C}(1)$ & 3.07 & 2.73 & 6.79 & $7.31 \%$ \\
\hline & $\mathrm{B}(0) \times \mathrm{C}(2)$ & 0.8 & 0.73 & 10 & $1.90 \%$ \\
\hline & $\mathrm{B}(1) \times \mathrm{C}(0)$ & 1.6 & 1.53 & 7.9 & $3.81 \%$ \\
\hline & $\mathrm{B}(2) \mathrm{X} C(0)$ & 0.4 & 0.4 & & $0.95 \%$ \\
\hline & $\mathrm{B}(1) \times \mathrm{C}(2)$ & 4.27 & 3.67 & 5.73 & $10.17 \%$ \\
\hline & $\mathrm{B}(2) \times \mathrm{C}(1)^{\mathrm{a})}$ & 13 & 7.67 & 2.61 & $30.95 \%$ \\
\hline
\end{tabular}

$\mathrm{N}=15$ participants

a) Primary attractors

b) Secondary attractors 
Primary attractors correspond, essentially, to states of absolute coordination at moderate levels of change, or states of relative coordination with high behavioural and cognitive changes but moderate emotional changes.

Figure 1 represents the evolution of the primary and secondary attractor through five periods of the training.

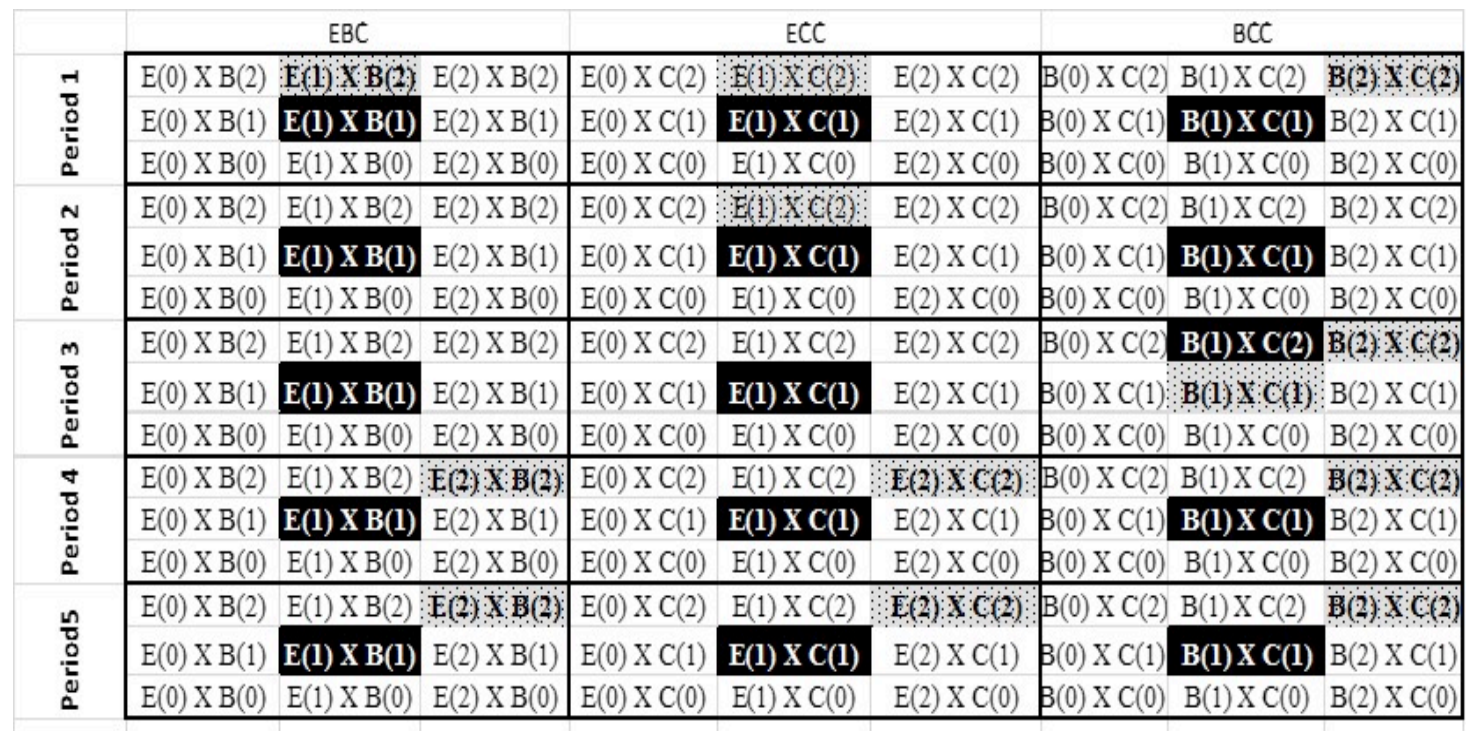

Primary attractors

Secondary attractors

Fig. 1

Representation of the primary and secondary attractors in the state spaces of coordination for five training periods, for the entire sample

Primary attractors remain stable. Coordination also appears to stabilize with the fixation of secondary attractors at high levels of change for the two final periods of the training.

We compared the distributions of the fluctuations and dispersion for each coordination space through the five periods (Fig. 2).

Kruskal-Wallis tests indicated statistically significant differences in fluctuations for EBC $\left(\chi^{2}(4)=22.02, p=.000\right), \operatorname{ECC}\left(\chi^{2}(4)=22.79, p=.000\right)$, and $\operatorname{BCC}\left(\chi^{2}(4)=25.18, p=.000\right)$.

There were also statistically significant differences for $\operatorname{ECC~}\left(\chi^{2}(4)=14.77, p=.005\right)$, dispersion and $\operatorname{BCC}\left(\chi^{2}(4)=16.36, p=.003\right)$, but not $\operatorname{EBC}\left(\chi^{2}(4)=4.64, p=.327\right)$.

Post-hoc Mann-Whitney tests, with Bonferroni corrections, revealed significant statistically differences in fluctuations, for some categories, between periods 1 and 3 (ECC: $U=$ $28.50 p=.000 ; \mathrm{BCC}: U=44.50, p=.004), 1$ and 4 (EBC: $U=20.50, p=.000$; ECC: $U=24.50$, $p=.001$; BCC: $U=21.00, p=.000)$, and 1 and 5 (EBC: $U=23.50, p=.001$; ECC: $U=23.50, p$ $=.001$; BCC: $U=20.00, p=.000$ ), as well as between 2 and 4 (EBC: $U=29.50, p=.002$ ) and 2 and 5 for some categories (BBC: $U=26.00, p=.001)$. Additionally, statistically significant differences were found between dispersion in period 1 and 3(ECC: $U=45.50, p=.004$ ), 1 and 5 (ECC: $U=32.50, p=.004$; BCC: $U=33.00, p=.004), 2$ and 5 (BBC: $U=31.00, p=.003$ ). 
Fluctuations in the coordination trajectories in the state spaces through five periods of the training

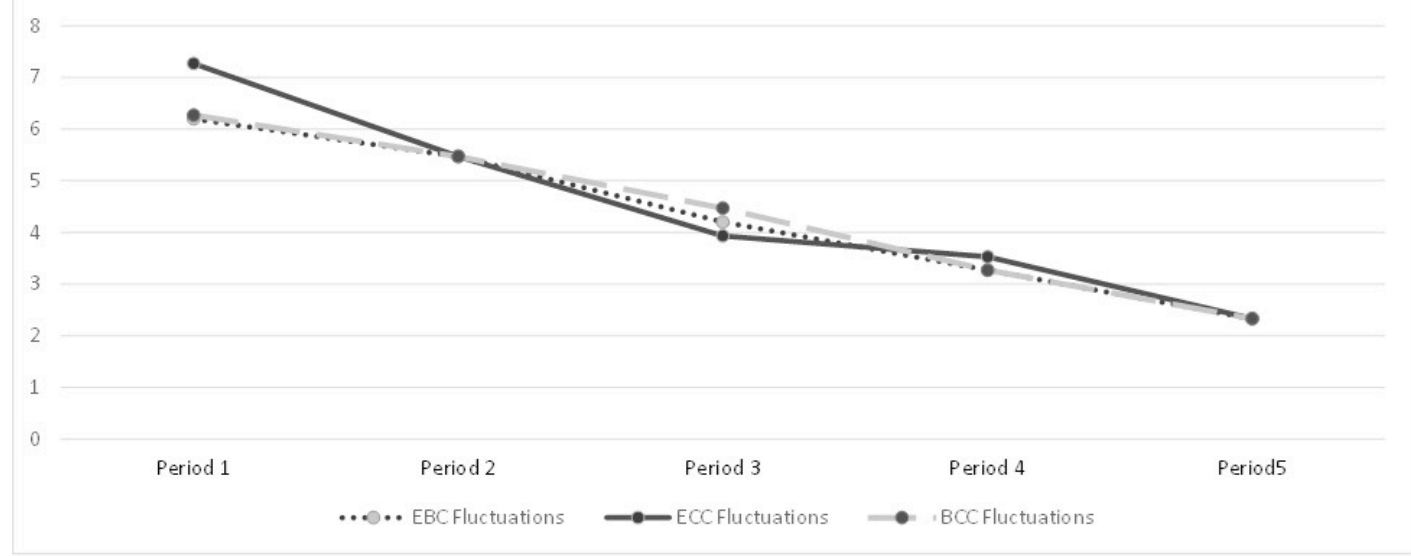

Dispersion of the coordination trajectories in the state spaces through five periods of the training

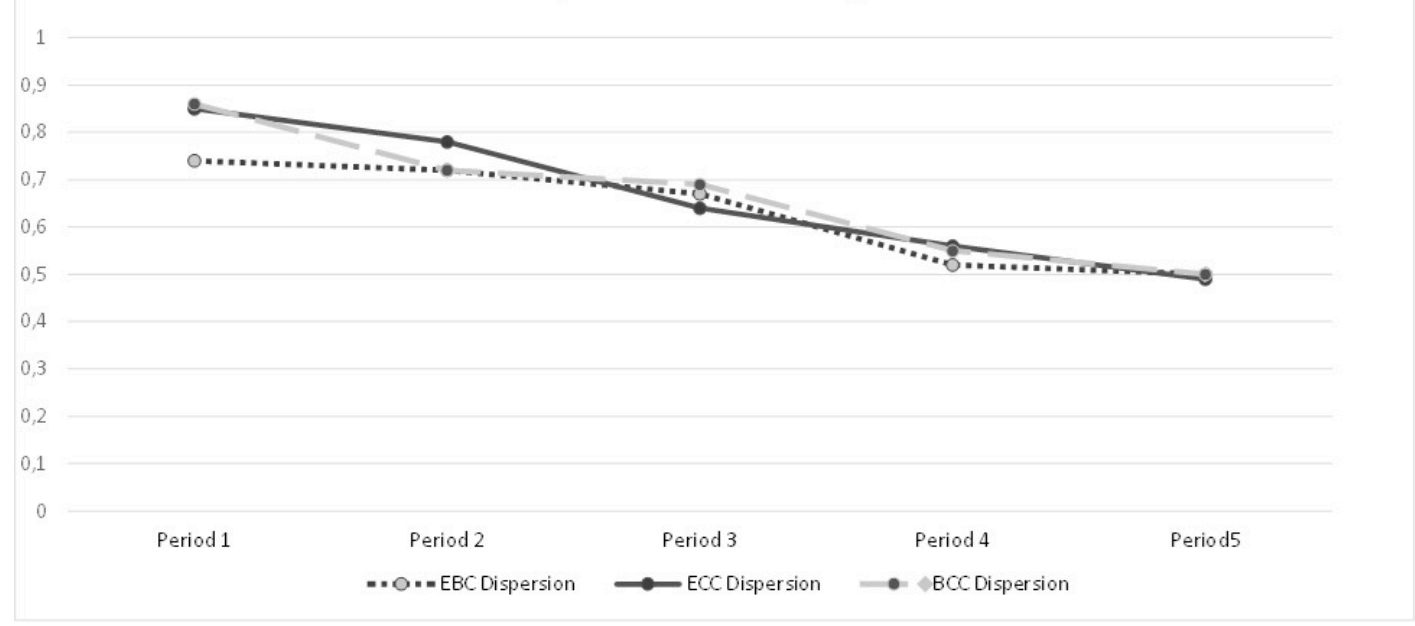

Figure 2

Distribution of the dispersion and fluctuations values of the coordination state spaces through five periods of the training

For some categories, there were no statistical significant differences in fluctuations between periods 1 and 2 (EBC: $U=67.50, p=.061$; ECC: $U=70.50, p=.081$; BCC: $U=94.00$, $p=.461), 1$ and 3 (EBC: $U=47.00, p=.006$ ), 2 and 3 (EBC: $U=65.50, p=.050$; ECC: $U=$ 63.00, $p=.041$; BCC: $U=53.50, p=.013$ ), 2 and 4 (ECC: $U=52.50, p=.054$; BCC: $U=30.50$, $p=.003) ; 2$ and 5 (EBC: $U=40.50, p=.014$; ECC: $U=48.50, p=.041), 3$ and 4 (EBC: $U=$ $78.00, p=.581$; ECC: $U=87.50, p=.905$; BCC: $U=68.00, p=.300), 3$ and 4 (EBC: $U=68.00$, $p=.300$; ECC: $U=82.00, p=.719$; BCC: $U=61.00, p=.167$ ), and 4 and 55 (EBC: $U=64.50$, $p=.671$; ECC: $U=62.50, p=.590$; BCC: $U=62.00, p=.590)$. The same was verified for dispersion between periods 1 and 2 (ECC: $U=106.00, p=.806$; $\mathrm{BCC}: U=105.00, p=.775), 1$ and 3 (BCC: $U=48.50, p=.007), 1$ and 4 (ECC: $U=55.50, p=.093$; $\mathrm{BCC}: U=41.00, p=$ 
.016 ), 2 and 3(ECC: $U=47.00, p=.006$; BCC: $U=61.00, p=.033$ ), 2 and 4 ECC: $U=65.50, p$ $=.236$; $\mathrm{BCC}: U=44.00, p=.025), 2$ and $5(U=37.00, p=.009), 3$ and 4 (ECC: $U=76.00, p=$ .516 ; BCC: $U=86.50, p=.867$ ); 3 and 5 (ECC: $U=86.50, p=.867$; $\mathrm{BCC}: U=77.00, p=.548$ ) and 4 and 5 (ECC: $U=56.00, p=.378$, BCC: $U=56.00, p=.378$ ).

Individual trajectories of change and change coordination. At the individual level, there was considerable diversity. Table $2 \mathrm{a}$ to $2 \mathrm{f}$ presents the properties of each of the participants' trajectories for the three categories of change and coordination. While for some participants there is internal consistency between the dimensions of change, for others there is some inconsistency.

Main attractors are, more frequently, states of absolute coordination at moderate levels, but there are exceptions. Secondary attractors exist both at high and low levels. Regarding dynamics, some trajectories end in multistable states while others stabilize in a primary core attractor. For some participants, there is change in the attractors' landscape while for others there are only transitions between primary and secondary attractors.

In order to identify change profiles we performed a series of hierarchical cluster analyses, at the case level, using the nearest neighbour clustering method and the Jaccard measure for binary data. For the matter, we transformed all variables into categorical binary variables (yes/no). The cluster analysis helped us identify the most informative variables. We used an iterative approach to perform a series of sequential analyses in which the results from the previous ones informed the inclusion or exclusion of some variables in the next ones.

The results were analysed regarding the variables' contribution for the best possible theoretically sound cluster solution. The addition, some variables did not result in relevant changes in the solution and, in some cases, their inclusion resulted in a solution of difficult interpretation, due to the absence of noticeable patterns in the relation to other variables. These variables were, therefore, excluded from latter steps. The selection of the number of clusters was based on the distance between them, according to the coefficients of the agglomeration schedule, and on the visual inspection of the dendogram. The analysis of the dendogram also informed the creation of sub-clusters.

A final solution, with 6 clusters, is illustrated in tables $2 \mathrm{a}$ to $2 \mathrm{f}$ through the allocation of each individual to a profile/cluster (letter) and sub-cluster (number after letter).

Profile A, corresponds to a pattern of Intensive, Highly Coordinated and Consistent Change Profile, with highlighted emotional and cognitive changes. It represents a fluctuant pattern of change marked very long periods of high emotional changes, which evolve around single primary attractors towards high levels of coordination. Cognitive and emotional changes and coordination also have high expression.

Profile B represents a Moderate, Consistent Change and Change Coordination Profile. These participants show a sort of committed and reliable change profile, a kind of "safe" learners. Changes are experienced in a quasi-continuous way, for very long periods of time, but at moderate levels of intensity. Two sub-profiles vary on the attractor dynamics. One sub-group shows tendency to stabilize in absolute coordination at moderate levels. The other shows a more unstable trajectory, evolving to multiple attractors and alternating between states of absolute coordination at high levels of change and relative coordination.

Profile C shows a sort of Mildly "Bumpy" trajectories or Moderate and Mildly Consistent Change Pattern, Tending Towards Stable Absolute Coordination. Participants report alternated isolated and very long periods of change interrupted by periods of low change. The process is mostly balanced but there are some fluctuant trajectories. 
Table 2a

Profiles and sub-profiles of change and properties of the participants' trajectories

\begin{tabular}{|c|c|c|c|c|c|}
\hline \multicolumn{2}{|c|}{$\begin{array}{l}\text { Participant } \\
\text { (Profile and } \\
\text { sub-profile)/ } \\
\text { Type of change }\end{array}$} & $\begin{array}{l}\text { Change } \\
\text { expressivity }\end{array}$ & $\begin{array}{l}\text { Patterns of change } \\
\text { continuity }\end{array}$ & $\begin{array}{l}\text { Pattern of } \\
\text { distribution of } \\
\text { changes }\end{array}$ & Pattern of change process \\
\hline \multirow{3}{*}{$\begin{array}{c}1 \\
(\mathrm{~A})\end{array}$} & $\mathrm{EC}$ & High & Quasi-continuous & Pred. VL & Fluctuant \\
\hline & $\mathrm{BC}$ & Moderate & Intermittent & Pred. VL & Fluctuant \\
\hline & $\mathrm{CC}$ & High & Quasi- continuous & Pred. VL & Balanced diverse \\
\hline \multirow{3}{*}{$\begin{array}{c}3 \\
(\mathrm{~B} 1)\end{array}$} & $\mathrm{EC}$ & Moderate & Quasi-continuous & Pred. VL & Balanced simple intermittent \\
\hline & $\mathrm{BC}$ & Moderate & Quasi-continuous & Pred. VL & Balanced simple intermittent \\
\hline & $\mathrm{CC}$ & Moderate & Quasi-continuous & Pred. VL & Fluctuant \\
\hline \multirow{3}{*}{$\begin{array}{c}5 \\
(\mathrm{~B} 1)\end{array}$} & $\mathrm{EC}$ & Moderate & Quasi-continuous & Pred. VL & Fluctuant \\
\hline & $\mathrm{BC}$ & Moderate & Quasi-continuous & Dom. VL & Fluctuant \\
\hline & $\mathrm{CC}$ & Moderate & Quasi-continuous & Dom VL & Balanced diverse \\
\hline \multirow{3}{*}{$\begin{array}{c}4 \\
(\mathrm{~B} 2)\end{array}$} & $\mathrm{EC}$ & High & Quasi-continuous & Dom. VL & Balanced simple intermittent \\
\hline & $\mathrm{BC}$ & Moderate & Intermittent & Dom. VL & Fluctuant \\
\hline & $\mathrm{CC}$ & Moderate & Quasi-continuous & Dom. VL & Balanced diverse \\
\hline
\end{tabular}

Note: The profile is represented by a letter and the sub-profile by the number

Dom: Dominance of; Pred: Predominance of; VL: Very long block period; Isolated: Isolated periods;

Table $2 b$

Profiles and sub-profiles of change and properties of the participants' trajectories (cont.)

\begin{tabular}{|c|c|c|c|c|c|c|c|}
\hline \multirow{2}{*}{\multicolumn{2}{|c|}{$\begin{array}{l}\text { Participant } \\
\text { (Profile and } \\
\text { sub-profile) / } \\
\text { Category of } \\
\text { coordination }\end{array}$}} & \multicolumn{2}{|c|}{ Main attractors } & \multicolumn{4}{|c|}{ Evolution of attractor dynamics in coordination space } \\
\hline & & \multirow[t]{2}{*}{$\begin{array}{l}\text { Atractor } 1 \\
\text { E1 X B1 }\end{array}$} & $\begin{array}{c}\text { Atractor } \\
2\end{array}$ & $\begin{array}{c}\text { Changes in } \\
\text { primary attractor }\end{array}$ & \multirow[t]{2}{*}{$\begin{array}{c}\text { Evolution } \\
\text { of the } \\
\text { number of } \\
\text { primary } \\
\text { attractor }\end{array}$} & $\begin{array}{c}\text { Transitions } \\
\text { between primary } \\
\text { and secondary } \\
\text { attractors }\end{array}$ & $\begin{array}{l}\text { Final tendency } \\
\text { (coordination } \\
\text { type and levels) }\end{array}$ \\
\hline 1 & $\mathrm{EBC}$ & & E2 X B2 & Changes to new & & $1^{\text {st }}-2$ nd & AC high \\
\hline \multirow[t]{3}{*}{ (A1) } & $\mathrm{ECC}$ & $\mathrm{E} 2 \mathrm{X} \mathrm{C} 2$ & E1 X C1 & Changes to new & Single & No transition & AC high \\
\hline & $\mathrm{BCC}$ & $\mathrm{B} 1 \mathrm{X} \mathrm{C} 1$ & $\mathrm{~B} 2 \mathrm{X} \mathrm{C} 2$ & Changes to new & Single & No transition & AC high \\
\hline & $\mathrm{EBC}$ & E1 X B1 & NA & Maintenance & Single & No secondary & AC mode \\
\hline \multirow{2}{*}{$\begin{array}{c}3 \\
(\mathrm{~B} 1) \\
\end{array}$} & $\mathrm{ECC}$ & $\mathrm{E} 1 \mathrm{X} \mathrm{C} 1$ & $\mathrm{E} 1 \mathrm{X} \mathrm{C} 2$ & Maintenance & Single & No secondary & AC moderate \\
\hline & $\mathrm{BCC}$ & $\mathrm{B} 1 \mathrm{X} \mathrm{C1}$ & NA & Maintenance & ingle; $\mathrm{M}-\mathrm{S}$ & No secondary & AC moderate \\
\hline \multirow{4}{*}{$\begin{array}{c}5 \\
(\mathrm{~B} 1)\end{array}$} & $\mathrm{EBC}$ & E1 X B1 & NA & Maintenance & Single & No transition & AC moderate \\
\hline & $\mathrm{ECC}$ & E1 X C1 & $\mathrm{E} 1 \mathrm{X} \mathrm{C} 2$ & Maintenance & Single & No transition & AC moderate \\
\hline & $\mathrm{BCC}$ & $\mathrm{B} 1 \mathrm{X} \mathrm{C1}$ & $\mathrm{B} 2 \mathrm{X} \mathrm{C} 2$ & Main, Return earlier & End. single & End. primary & AC moderate \\
\hline & $\mathrm{EBC}$ & E1 X B1 & NA & Changes to new & S-M & No & gh; RC high $\mathrm{BC} / \mathrm{EC}$ \\
\hline \multirow{2}{*}{$\begin{array}{c}4 \\
(\mathrm{~B} 2)\end{array}$} & $\mathrm{ECC}$ & E1 X C1 & $\mathrm{E} 1 \mathrm{X} \mathrm{C} 2$ & Changes to new & S-M & AC hi & gh; RC high EC/CG \\
\hline & $\mathrm{BCC}$ & B1 X C1 & $\mathrm{B} 2 \mathrm{X} \mathrm{C} 2$ & To earlier & nultiple & d. primary & igh; $\mathrm{RC}$ high $\mathrm{BC} / \mathrm{CC}$ \\
\hline
\end{tabular}

Note: The profile is represented by a letter and the sub-profile by the number

EBC: emotional-behaviour coordination; ECC: Emotional-cognitive coordination; BCC: behavioural-cognitive coordination;

S-M: Single to multiple; M-S: Multiple to single; 1 st- $2^{\text {nd }}$ : Primary to secondary; End: Variations ending in; Return: variations with return to 
Table 2c

Profiles and sub-profiles of change and properties of the participants' trajectories (cont.)

\begin{tabular}{|c|c|c|c|c|c|}
\hline \multicolumn{2}{|c|}{$\begin{array}{l}\text { Participant } \\
\text { (Profile and sub- } \\
\text { profile)/ Type of } \\
\text { change }\end{array}$} & $\begin{array}{l}\text { Change } \\
\text { expressivity }\end{array}$ & $\begin{array}{l}\text { Patterns of change } \\
\text { continuity }\end{array}$ & $\begin{array}{l}\text { Pattern of distribution of } \\
\text { changes }\end{array}$ & $\begin{array}{l}\text { Pattern of change } \\
\text { process }\end{array}$ \\
\hline \multirow{3}{*}{$\begin{array}{c}6 \\
(\mathrm{C} 1)\end{array}$} & $\mathrm{EC}$ & Moderate & EC: Quasi-continuous & Mixed Pred. VL and I & Balanced diverse \\
\hline & $\mathrm{BC}$ & Moderate & BC: Intermittent & Mixed Pred. I and S & Balanced diverse \\
\hline & $\mathrm{CC}$ & Moderate & CC: Quasi-continuous & Mixed Dom. VL and I & Balanced simple sequential \\
\hline \multirow{3}{*}{$\begin{array}{c}7 \\
(\mathrm{C} 1)\end{array}$} & $\mathrm{EC}$ & Moderate & EC: Quasi-continuous & Mixed Pred. VL and I & Fluctuant \\
\hline & $\mathrm{BC}$ & Moderate & BC: Intermittent & Mixed Pred. VL and I & Balanced simple sequential \\
\hline & $\mathrm{CC}$ & High & CC: Intermittent & Mixed Pred. VL and I & Fluctuant \\
\hline \multirow{3}{*}{$\begin{array}{c}8 \\
(\mathrm{C} 2)\end{array}$} & EC & Moderate & EC: Intermittent & Mixed Pred. VL and I & Fluctuant \\
\hline & $\mathrm{BC}$ & Moderate & BC: Intermittent & Mixed Pred. VL and I & Fluctuant \\
\hline & $\mathrm{CC}$ & Moderate & CC: Intermittent & Mixed without pred. & Balanced simple sequential \\
\hline \multirow{3}{*}{$\begin{array}{c}9 \\
(\mathrm{C} 2)\end{array}$} & EC & Moderate & EC: Intermittent & Mixed Pred. VL and I & Balanced diverse \\
\hline & $\mathrm{BC}$ & Moderate & BC: Intermittent & Mixed without pred. & Balanced simple sequential \\
\hline & $\mathrm{CC}$ & Moderate & CC: Intermittent & Mixed Dom. VL and I & Balanced diverse \\
\hline
\end{tabular}

Note: The profile is represented by a letter and the sub-profile by the number

Legend: Dom: Dominance of; Pred.: Predominance of; VL: Very long block periods; I: Isolated periods; S: Short periods;

Table 2d

Profiles and sub-profiles of change and properties of the participants' trajectories (cont.)

\begin{tabular}{|c|c|c|c|c|c|c|c|}
\hline \multirow{2}{*}{\multicolumn{2}{|c|}{$\begin{array}{l}\text { Participant } \\
\text { (Profile and } \\
\text { sub-profile) / } \\
\text { Category of } \\
\text { coordination }\end{array}$}} & \multicolumn{2}{|c|}{ Main attractors } & \multicolumn{4}{|c|}{ Evolution of attractor dynamics in coordination space } \\
\hline & & $\begin{array}{c}\text { Atractor } \\
1\end{array}$ & $\begin{array}{c}\text { Atractor } \\
2\end{array}$ & $\begin{array}{l}\text { Changes in } \\
\text { primary } \\
\text { attractor }\end{array}$ & $\begin{array}{l}\text { Evolution of the } \\
\text { number of primary } \\
\text { attractor }\end{array}$ & $\begin{array}{l}\text { Transitions } \\
\text { between primary } \\
\text { and secondary } \\
\text { attractors }\end{array}$ & $\begin{array}{l}\text { Final } \\
\text { tendency }\end{array}$ \\
\hline \multirow{3}{*}{$\begin{array}{c}6 \\
(\mathrm{C} 1)\end{array}$} & $\mathrm{EBC}$ & E1 X B1 & E2 X B2 & Change to new & End. single & No transition & AC high \\
\hline & $\mathrm{ECC}$ & $\mathrm{E} 1 \mathrm{X} \mathrm{C1}$ & $\mathrm{E} 2 \mathrm{X} \mathrm{C} 2$ & Change to new & Single & No transition & AC high \\
\hline & $\mathrm{BCC}$ & B1 X C1 & $\mathrm{B} 2 \mathrm{X} \mathrm{C} 2$ & Change to new & Single & No transition & AC high \\
\hline \multirow{3}{*}{$\begin{array}{c}7 \\
(\mathrm{C} 2)\end{array}$} & $\mathrm{EBC}$ & E1 X B1 & E2 X B2 & Change to new & Single & No transition & AC low \\
\hline & $\mathrm{ECC}$ & $\mathrm{E} 1 \mathrm{X} \mathrm{C} 1$ & $\mathrm{E} 2 \mathrm{X} \mathrm{C} 2$ & Change to new & Single & No transition & AC low \\
\hline & $\mathrm{BCC}$ & B1 X C1 & $\mathrm{B} 0 \mathrm{X} \mathrm{C0}$ & Change to new & Single & No transition & AC low \\
\hline \multirow{3}{*}{$\begin{array}{c}8 \\
(\mathrm{C} 3)\end{array}$} & $\mathrm{EBC}$ & E1 X B1 & E0 X B0 & Maintenance & Single & No transition & AC moderate \\
\hline & $\mathrm{ECC}$ & E1 X C1 & NA & Return earlier & End. single & $2^{\text {nd }}-1^{\text {st }}$ & AC moderate \\
\hline & $\mathrm{BCC}$ & $\mathrm{B} 1 \mathrm{X} \mathrm{C1}$ & NA & Return earlier & End. single & End. primary & AC moderate \\
\hline \multirow{3}{*}{$\begin{array}{c}9 \\
(\mathrm{C} 3)\end{array}$} & $\mathrm{EBC}$ & E1 X B1 & E0 X B0 & Change to new & Single & No transitions & AC moderate \\
\hline & $\mathrm{ECC}$ & E1 X C1 & E0 X C0 & Change to new & $\checkmark$ Single & No transitions & AC moderate \\
\hline & $\mathrm{BCC}$ & B1 X C1 & $\mathrm{BO} \times \mathrm{C} 0$ & Change to new & Single & End. primary & AC moderate \\
\hline
\end{tabular}

Note: The profile is represented by a letter and the sub-profile by the number

Legend: EBC: emotional-behaviour coordination; ECC: Emotional-cognitive coordination; BCC: behaviouralcognitive coordination;

S-M: Single to multiple; M-S: Multiple to single; 1 st- $2^{\text {nd }}$ : Primary to secondary; $2^{\text {nd }}-1^{\text {st }}$ : Secondary to primary; End: Variations ending in; Return: variations with return to 
Table 2e

Profiles and sub-profiles of change and properties of the participants' trajectories (cont.)

\begin{tabular}{|c|c|c|c|c|c|}
\hline \multicolumn{2}{|c|}{$\begin{array}{l}\text { Participant } \\
\text { (Profile and } \\
\text { sub-profile)/ } \\
\text { Type of change }\end{array}$} & $\begin{array}{c}\text { Change } \\
\text { expressivity }\end{array}$ & $\begin{array}{c}\text { Patterns of } \\
\text { change continuity }\end{array}$ & $\begin{array}{l}\text { Pattern of distribution of } \\
\text { changes }\end{array}$ & $\begin{array}{l}\text { Pattern of change } \\
\text { process }\end{array}$ \\
\hline \multirow{3}{*}{$\begin{array}{l}12 \\
(\mathrm{D})\end{array}$} & EC & Moderate & EC: Intermittent & Mixed Pred. VL and I & Fluctuant \\
\hline & $\mathrm{BC}$ & Moderate & BC: Intermittent & Mixed Pred. VL and I & Fluctuant \\
\hline & $\mathrm{CC}$ & Moderate & CC: Quasi-continuous & Mixed Dom. VL and I & Fluctuant \\
\hline \multirow{3}{*}{$\begin{array}{l}2 \\
\text { (D) }\end{array}$} & $\mathrm{EC}$ & Moderate & EC: Quasi-continuous & Mixed Pred. VL and I & Fluctuant \\
\hline & $\mathrm{BC}$ & Moderate & BC: Intermittent & Mixed Pred. VL and I & Balanced diverse \\
\hline & $\mathrm{CC}$ & Moderate & CC: Quasi-continuous & Pred. VL & Balanced diverse \\
\hline \multirow{3}{*}{$\begin{array}{l}10 \\
(\mathrm{E})\end{array}$} & $\mathrm{EC}$ & High & EC: Intermittent & Mixed Dom. VL and I & Balanced simple intermittent \\
\hline & $\mathrm{BC}$ & Moderate & BC: Intermittent & Mixed Pred. VL and I & Fluctuant \\
\hline & $\mathrm{CC}$ & High & CC: Intermittent & Mixed Pred. VL and I & Balanced simple intermittent \\
\hline \multirow{3}{*}{$\begin{array}{l}11 \\
(\mathrm{~F})\end{array}$} & $\mathrm{EC}$ & Moderate & EC: Quasi-continuous & Mixed Dom VL and S & Balanced simple sequential \\
\hline & $\mathrm{BC}$ & Moderate & BC: Intermittent & Pred. VL & Fluctuant \\
\hline & $\mathrm{CC}$ & High & CC: Quasi-continuous & Pred. VL & Balanced simple sequential \\
\hline
\end{tabular}

Note: The profile is represented by a letter and the sub-profile by a number

Legend: Dom: Dominance of; Pred.: Predominance of; VL: Very long block periods; I: Isolated periods; S: Short periods.

Table 2f

Profiles and sub-profiles of change and properties of the participants' trajectories (cont.)

\begin{tabular}{|c|c|c|c|c|c|c|c|}
\hline \multirow{2}{*}{\multicolumn{2}{|c|}{$\begin{array}{l}\text { Participant } \\
\text { (Profile and } \\
\text { sub-profile) / } \\
\text { Category of } \\
\text { coordination }\end{array}$}} & \multicolumn{2}{|c|}{ Main attractors } & \multicolumn{4}{|c|}{ Evolution of attractor dynamics in coordination space } \\
\hline & & \multirow{2}{*}{$\begin{array}{c}\text { Atractor } \\
1 \\
\text { E1 X B1 }\end{array}$} & \multirow{2}{*}{$\begin{array}{c}\text { Atractor } \\
2 \\
\\
\text { E1 X B2 }\end{array}$} & \multirow{2}{*}{$\begin{array}{l}\text { Changes in primary } \\
\text { attractor } \\
\text { Change to new }\end{array}$} & \multirow{2}{*}{$\begin{array}{l}\text { Evolution of } \\
\text { the number of } \\
\text { primary } \\
\text { attractor } \\
\text { Single }\end{array}$} & \multirow{2}{*}{$\begin{array}{l}\text { Transitions } \\
\text { between } \\
\text { primary and } \\
\text { secondary } \\
\text { attractors } \\
2^{\text {nd }}-1^{\text {st }}\end{array}$} & \multirow{2}{*}{$\begin{array}{l}\text { Final tendency } \\
\text { Not applicable }\end{array}$} \\
\hline 12 & $\mathrm{EBC}$ & & & & & & \\
\hline & $\mathrm{ECC}$ & E1 X C1 & E1 X C2 & Change to new & S-M & $2^{\text {nd }}-1^{\text {st }}$ & AC moderate \\
\hline & $\mathrm{BCC}$ & $\mathrm{B} 1 \mathrm{X} \mathrm{C} 1$ & $\mathrm{~B} 2 \mathrm{X} \mathrm{C} 1$ & Change to new & S-M & transition; $2^{\text {nd }}-1^{\text {st }}$ & $\mathrm{AC} \mathrm{mo}$ \\
\hline \multirow{3}{*}{$\begin{array}{c}2 \\
\text { (D) }\end{array}$} & $\mathrm{EBC}$ & E1 X B1 & E0 X B0 & Return earlier & M-S & $2^{\text {nd }}-1^{\text {st }}$ & Not applicable \\
\hline & $\mathrm{ECC}$ & $\mathrm{E} 1 \mathrm{X} \mathrm{C} 1$ & $\mathrm{E} 2 \mathrm{X} \mathrm{C} 1$ & Changes to new & M-S & $2^{\text {nd }}-1^{\text {st }}$ & Not applicable \\
\hline & $\mathrm{BCC}$ & $\mathrm{B} 1 \mathrm{X} \mathrm{C1}$ & $\mathrm{B} 2 \mathrm{X} \mathrm{C1}$ & Maint.;changes to new & End. multiple & No transition & Not applicable \\
\hline & EBC & E0 X B0 & E2 X B2 & Change to new & End. multiple & No transitions & Not \\
\hline \multirow{2}{*}{ (E) } & ECC & $\mathrm{E} 2 \mathrm{X} \mathrm{C} 2$ & E0 X C0 & Change to new & End. single & itions & Not \\
\hline & $\mathrm{BCC}$ & B2 X C2 & E0 X C0 & Change to new & End. single & No transitions & plicable \\
\hline \multirow{3}{*}{$\begin{array}{c}11 \\
(\mathrm{~F})\end{array}$} & EBC & E1 X B1 & E2 X B2 & Change to new & End. single & No transitions & $\mathrm{ACl}$ \\
\hline & ECC & E1 X C2 & E2 X C2 & Change to new & M-S & rimary & Not applicable \\
\hline & $\mathrm{BCC}$ & $\mathrm{B} 2 \mathrm{X} \mathrm{C} 2$ & B1 X C1 & Change to new & M-S & $2^{\text {nd }}-1^{\text {st }}$ & AC high \\
\hline
\end{tabular}

Note: The profile is represented by a letter and the sub-profile by the number

Legend: EBC: emotional-behaviour coordination; ECC: Emotional-cognitive coordination; BCC: behaviouralcognitive coordination;

S-M: Single to multiple; M-S: Multiple to single; $1 \mathrm{st}-2^{\text {nd }}$ : Primary to secondary; $2^{\text {nd }}-1^{\text {st }}$ : Secondary to primary; End:

Variations ending in; Return: variations with return to 
Although evolving to stable states of absolute coordination, one sub-profiles evolve to low change, and others in moderate and high levels of change.

Profile D show a Hibrid Moderate Profile with highlighted cognitive changes and no clear final tendencies of coordination. Moderate levels of change occur during very long and isolated periods of change. The process of change is mostly fluctuant but balanced diverse patterns are also present. There are disparate states of coordination with different forms of evolution and either no clear final tendencies or a stabilization of absolute coordination at moderate levels.

Profile E is a sort of Hibrid "Bumpy Profile", highlighted emotional-cognitive changes and absolute coordination at mixed levels of change, with undefined final coordination tendencies. While high levels of emotional and cognitive changes occur during long or isolated periods of change, interspersed with periods of stability, behavioural changes exhibit more fluctuations but mostly moderate levels of change. The coordination is mostly absolute at different levels of change and oscillates during the trajectory without a defined final tendency.

Profile F is a Hybrid Mildly Consistent Profile with highlighted cognitive changes and stable behavioural coordination. The process of change is marked by the alternation of long periods of stability and fluctuation, but changes are quasi-continuous for the emotional and cognitive dimensions. Cognitive changes are high and coordination also favours states with high cognitive changes. Coordination implying behavioural changes stabilizes- at high levels- but cognitive-emotional coordination does not.

\section{Discussion}

In this study, a coding scheme to describe change and change coordination processes was develop and presented potential for application in other fields. It allowed the identification of change profiles based on the structural and dynamical features of the trajectories of change and the coordination of changes of professionals participating in a specialized educational program.

On the other hand, the results highlight interesting aspects of the change/learning processes and the coordination of emotional, behavioural and cognitive changes. The limitations of this study limit the conclusions. They include a limited sample size, the lack of a control group and the impossibility of establishing any causal links between the program and the participants' reports. Additionally, reports of change are abstract, with no subjective content. Nevertheless, some interesting hypothesis emerged.

The results indicate that the participants experienced more emotional and cognitive than behavioural changes. Previous evaluations of the educational program revealed slow behavioural changes. Although we did not compare the results with objective measures of the participants' performance this should be inspected in the future. It is possible that behavioural changes need more time to appear and stabilize. Nevertheless, there may be other external constrains to behavioural changes (e.g. difficulties posed by the families; team composition, etc.) which should be investigated in the future. This reinforces the need for long-term programs and special attention to the changes that facilitate behavioural ones. Although there are no differences between levels of emotional and cognitive changes, absolute emotional-cognitive coordination was less frequent than emotional-behavioural and behavioural-cognitive coordination. These results suggest that the challenges implied in learning/changing throughout a program with objectives such as ours, may be not so much in the elicitation of changes per se, but in their coordination. Behavioural changes may depend on the relationship between emotions and cognitive form, and may, somehow, represent the quality of the bridge between the two. 
The results show a global preference for states absolute of coordination at moderate levels. There may be different explanations for this, which deserve further testing. On the one hand, it is possible that the programs' extended length, the components aimed at personal development, the emotional support from the group and each ones' team, as well as the facilitator's scaffolding contributed too keep changes at an acceptable level and well coordinated. On the other hand, it is possible that, more or less independently of the program, those are the most manageable or favourable states for one to cope with during the training. An analysis of the evolution of the coordination state spaces suggests that the process of change stabilizes towards the end of the training with the fixation, as secondary attractors, of states of absolute coordination at high levels. It is possible that the first months of the program are associated with more disturbance and that it takes some time until the participants can stabilize in highly coordinated states. Although we lack subjective information, this possibility is congruent with previous studies indicating that the first months of training were the most distressing due to the novelty of changes and the difficulties in adapting to them. The decreases in fluctuations and dispersion reinforce the idea of a progressive stabilization in the coordination of changes.

Nevertheless, the diversity, at the level of the individual trajectories, calls attention to the systemic properties of multi and equifinality of the change/learning process. Most pathways of change are marked by fluctuations, either above stability or in balance with it, but the levels of intensity differ. The preferred states of coordination throughout the trajectory are not necessarily the end ones and the transitions between attractors differ between participants. While for some participants the number of preferred states decreases, others end the training with multiple stable states. The demands of supporting participants with a different profile of change are probably different. Individualized support was provided during the training, which might have influenced the results. However, a possible indicator of success of the support provided may be the existence of a final coordination tendency, suggesting a stabilization of the change process. The results call for individualized attention from the program's facilitators, in order to identify and support participants regarding those aspects that pose more difficulties for each. For example, those with intense and almost continuous patterns of change will possibly experience more difficulties in keeping the pace, without excessive effort, but may also retrieve more satisfaction. On the other hand, those who change moderately and intermittently may face more difficulties in keeping themselves engaged in learning, possibly benefiting from external incentives (Rathunde \& Csikszentmihalyi, 2006). Those that experience changes in the different dimensions, at disparate levels, may face other sort of challenges which need to be better understood in future studies. The facilitator role may be important in helping participants stabilize the coordination of changes. The coding framework that was developed may have applications during the educational programs for the adjustment of educational practices. This study was limited in scope. However, future studies should compare the change profiles with detailed reports of the participants' subjective experiences and objective performance outcomes. Future studies should also compare the structural and dynamical features of change and change coordination in different types of learning and change promotion settings. 


\section{References}

Charmaz, K. (2006). Constructing grounded theory. A practical guide through qualitative analysis. London: Sage.

Elkaïm, M. (comp.) (1988). Formaciones y prácticas en terapia familiar. Buenos Aires: Ediciones Nueva Visión.

Fogel, A. (2011). Theoretical and applied dynamic systems research in developmental science. Child Development Perspectives, 5(4), 267-272. Hertfordshire: Harvester Wheatsheaf. doi: $10.1111 / \mathrm{j} .1750-8606.2011 .00174 . \mathrm{x}$

Glaser, B. G., \& Strauss, A. L. (2008). The discovery of grounded theory: Strategies for qualitative research. New Brunswick: Aldine Transaction. Originally published in 1967.

Graesser, A. C., \& D'Mello, S., (2012) Emotions during the learning of difficult material. In B. H. Ross (Ed.), Psychology of learning and motivation, Volume 57 (pp. 183-226). San Diego, CA: Academic Press.

Granic, I., \& Hollenstein, T. (2003). Dynamic systems methods for models of developmental psychopathology. Development and Psychopathology, 15, 641-669.

Guastello, S. J., Koopmans, M., \& Pincus, D. (2009). Chaos and complexity in psychology. The theory of nonlinear dynamical systems. New York: Cambridge University Press.

Hollenstein, T. (2011). Twenty years of dynamic systems approaches to development: Significant contributions, challenges and future directions. Child Development Perspectives, 5(4), 256-259. doi: 10.1111/j.1750-8606.2011.00210.x

Lamey, A., Hollenstein, T., Lewis, M. D., \& Granic, I. (2004). Gridware (Version 1.1) [Computer software]. http://www.statespacesgrids.org.

Lewis, M. (2000). The promise of dynamic systems approaches for an integrated account of human development. Child Development,71(1), 36-43. doi: 10.1111/1467-8624.00116

Nel, P. W. (2006). Trainee perspectives of their family therapy training. Journal of Family Therapy, 28, 307-328. doi: 10.1111/j.1467-6427.2006.00354.x

Rathunde, K., \& Csikszentmihalyi, M. (2006). The developing person: An experiential perspective. In R. M. Lerner, \& W. Damon (Eds.), Handbook of child psychology. Volume 1. Theoretical models of human development ( $6^{\text {th }}$ edition) (pp.465-515). New Jersey: John Wiley \& Sons.

Sharlin, S. A., \& Shamai, M. (2000). Therapeutic intervention with poor, unorganized families. From distress to hope. New York: The Haworth Clinical Practice Press.

Stamovlasis, D., \& Koopmans, M. (2014). Editorial introduction: Education is a Dynamical System. Nonlinear Dynamics, Psychology, and Life Sciences, 18(1), 1-4.

Strauss, A. L. (1987). Qualitative analysis for social scientists. New York: Cambridge University Press.

Thelen, E., \& Smith, L. (2006). Dynamic systems theories. In R. M. Lerner, \& W. Damon(Eds.), Handbook of child psychology. Volume 1. Theoretical models of human development $\left(6^{\text {th }}\right.$ edition). (pp.258-312). New Jersey: John Wiley \& Sons.

Van Geert, P. (2011). The contribution of complex dynamic systems to development. Child Development Perspectives, 5(4), 273-278. doi: 10.1111/j.1750-8606.2011.00197.x

Van Geert, P. (2012). Dynamic systems. In B. Laursen, T. D. Little, N. A. Card (Eds.), Handbook of developmental research methods (pp. 725-741). The Guildford Press.

Wettstein, A., \& Thommen, B. (2009). Dynamic methods for research in education. In J. Valsiner, P. C. M. Molenaar, M. C. D. P. Lyra, \& N. Chaudhary (Eds.) Dynamic process 
methodology in the social and developmental sciences (pp. 533-382). New York: Springer.

\section{Acknowledgments}

The first author was supported by a post-doctoral fellowship attributed by the Portuguese Foundation of Science of ([insert reference]). The authors wish to thank all participants and their institutions. 


\section{Appendix A}

List of codes for core categories, sub-categories and their properties

Properties of change

Type of change

Emotional change (EC)

Behavioural change $(B C)$

Cognitive change (CC)

Level of change

Low or (0)

Moderate or (1)

High or (2)

Properties of the change trajectories

Change reactivity

Low

Moderate

High

Change expressivity

Low

Moderate

High

Relative properties of the change trajectories

Change predominance

Predominance of emotional changes

Predominance of behavioural changes

Predominance of cognitive changes

Mixed predominance of $X$ and $Y$ (specify)

No predominance

Change salience

Salience of one type of change (specify)

Mixed salience of $X$ and $Y$ (specify)

No salience

Change patterns

Patterns of change continuity

Pattern of continuous changes

Pattern of quasi-continuous changes

Pattern of intermittent changes

Patterns of distribution of changes

Pattern of dominance of isolated periods of change

Pattern of dominance of short periods of change

Pattern of dominance of long periods of change

Pattern of dominance of very long periods of change

Mixed pattern of dominance of $X$ and $Y$ (specify)

Pattern of predominance of isolated periods of change

Pattern of predominance of short periods of change

Pattern of predominance of long periods of change

Pattern of predominance of very long periods of change

Mixed pattern with predominance of X and $Y$ (specify)

Mixed pattern without predominance

(Each type may or may not present secondary patterns)

Change dynamics

Size of fluctuations

Small fluctuations

Large fluctuations

Mixed size fluctuations

Duration of fluctuations

Isolated periods of fluctuations

Short periods of fluctuations

Long periods of fluctuations

Very long periods of fluctuations

Pattern of organization of fluctuations

Pattern of dominance of isolated small fluctuations (fl.) 
Pattern of dominance of isolated large $\mathrm{fl}$.

Pattern of dominance of isolated mixed sizes $f l$.

Pattern of predominance of isolated small fl.

Pattern of predominance of isolated large $f l$.

Pattern of predominance of isolated mixed sizes $f l$.

Pattern of dominance of short periods of small fl.

Pattern of dominance of short periods of large $f l$.

Pattern of dominance of short periods of mixed sizes $f l$.

Pattern of predominance of short periods of small fl.

Pattern of predominance of short periods of large fl.

Pattern of predominance of short periods of mixed sizes $\mathrm{fl}$.

Pattern of dominance of long block periods of small $\mathrm{fl}$.

Pattern of dominance of very long block periods of large $\mathrm{fl}$.

Pattern of dominance of long block periods of mixed sizes $\mathrm{fl}$.

Pattern of predominance of long block periods of small $f l$.

Pattern of predominance of long block periods of large $f$.

Pattern of predominance of long block periods of mixed sizes $\mathrm{fl}$.

Pattern of dominance of very long block periods of small $f l$.

Pattern of dominance of very long block periods of large $\mathrm{fl}$.

Pattern of dominance of very long block periods of mixed sized fl.

Pattern of predominance of very long block periods of small fl.

Pattern of predominance of very long block periods of large fl.

Pattern of predominance of very long block periods of mixed sized $f l$.

Mixed pattern of dominance of $X$ and $Y$ (specify) of small fl.

Mixed pattern of dominance of $X$ and $Y$ (specify) of large $f l$.

Mixed pattern of dominance of $X$ and $Y$ (specify) of mixed sized $f l$.

Mixed pattern of predominance of $X$ and $Y$ (specify) of small $f l$.

Mixed pattern of predominance of $X$ and $Y$ (specify) of large $f l$.

Mixed pattern of predominance of $X$ and $Y$ (specify) of mixed sized $f l$.

Mixed pattern without predominance of small $\mathrm{fl}$.

Mixed pattern without predominance of large $f l$.

Mixed pattern without predominance of mixed sized fl.

All patterns may or may not be classified with secondary patterns.

Level of stability

Stability at low levels of change

Stability at moderate levels of change

Stability at high levels of change

Stability at mixed levels of change

Duration of stability

Isolated periods of stability

Short periods of stability

Long periods of stability

Very long periods of stability

Pattern of organization of stability

Pattern of dominance of isolated periods of stability at low levels of change (loc)

Pattern of dominance of isolated periods of stability at moderate loc

Pattern of dominance isolated periods of stability at high loc

Pattern of dominance isolated periods of stability at mixed loc

Pattern of predominance of isolated periods of stability at low loc

Pattern of predominance of isolated periods of stability at moderate loc

Pattern of predominance isolated periods of stability at high loc

Pattern of predominance isolated periods of stability at mixed loc

Pattern of dominance of short periods of stability at low loc

Pattern of dominance of short periods of stability at moderate loc

Pattern of dominance of short periods of stability at high loc

Pattern of dominance of short periods of stability at mixed loc

Pattern of predominance of short periods of stability at low loc

Pattern of predominance of short periods of stability at moderate loc

Pattern of predominance of short periods of stability at high loc

Pattern of predominance of short periods of stability at mixed loc

Pattern of dominance of long block periods of stability at low loc

Pattern of dominance of long block periods of stability at moderate loc 
Pattern of dominance of long block periods of stability at high loc

Pattern of dominance of long block periods of stability at mixed loc

Pattern of predominance of long block periods of stability at low loc

Pattern of predominance of long block periods of stability at moderate loc

Pattern of predominance of long block periods of stability at high loc

Pattern of predominance of long block periods of stability at mixed loc

Pattern of dominance of very long block periods of stability at low loc

Pattern of dominance of very long block periods of stability at moderate loc

Pattern of dominance of very long block periods of stability at high loc

Pattern of dominance of very long block periods of stability at mixed loc

Pattern of predominance of very long block periods of stability at low loc

Pattern of predominance of very long block periods of stability at moderate loc

Pattern of predominance of very long block periods of stability at high loc

Pattern of predominance of very long block periods of stability at mixed loc

Mixed pattern of dominance of $X$ and $Y$ (specify)

Mixed pattern of predominance of $X$ and $Y$

Mixed without predominance

Pattern of change processes

Balanced simple sequential pattern

Balanced simple intermittent pattern

Balanced diverse pattern

Fluctuant pattern

Stable pattern

Unstable pattern

Static pattern

\section{Coordination of changes}

Category of change coordination

Emotional-Behavioural coordination (EBC)

Emotional-Cognitive coordination (ECC)

Behavioural-Cognitive coordination (BCC)

Type of coordination

Absolute coordination (AC)

Relative coordination ( $R C)$

Incoordination (IC)

States of coordination

States of absolute EBC

$E(2) X B(2)$

$E(1) X B(1)$

$E(0) X B(0)$

States of absolute ECC

$E(2) X C(2)$

$E(1) X C(1)$

$E(0) X C(0)$

States of absolute $B C C$

$B(2) X C(2)$

$B(1) X C(1)$

$B(0) X C(0)$

States of relative $E B C$

$E(1) X B(2)$

$E(2) X B(1)$

States of relative ECC

$E(1) X C(2)$

$E(2) X C(1)$

States of relative $B C C$

$B(1) X C(2)$

$B(2) X C(1)$

States of EBC incoordination

$E(1) X B(0)$

$E(2) X B(0)$

$E(0) X B(1)$

$E(0) X B(2)$

States of ECC incoordination 


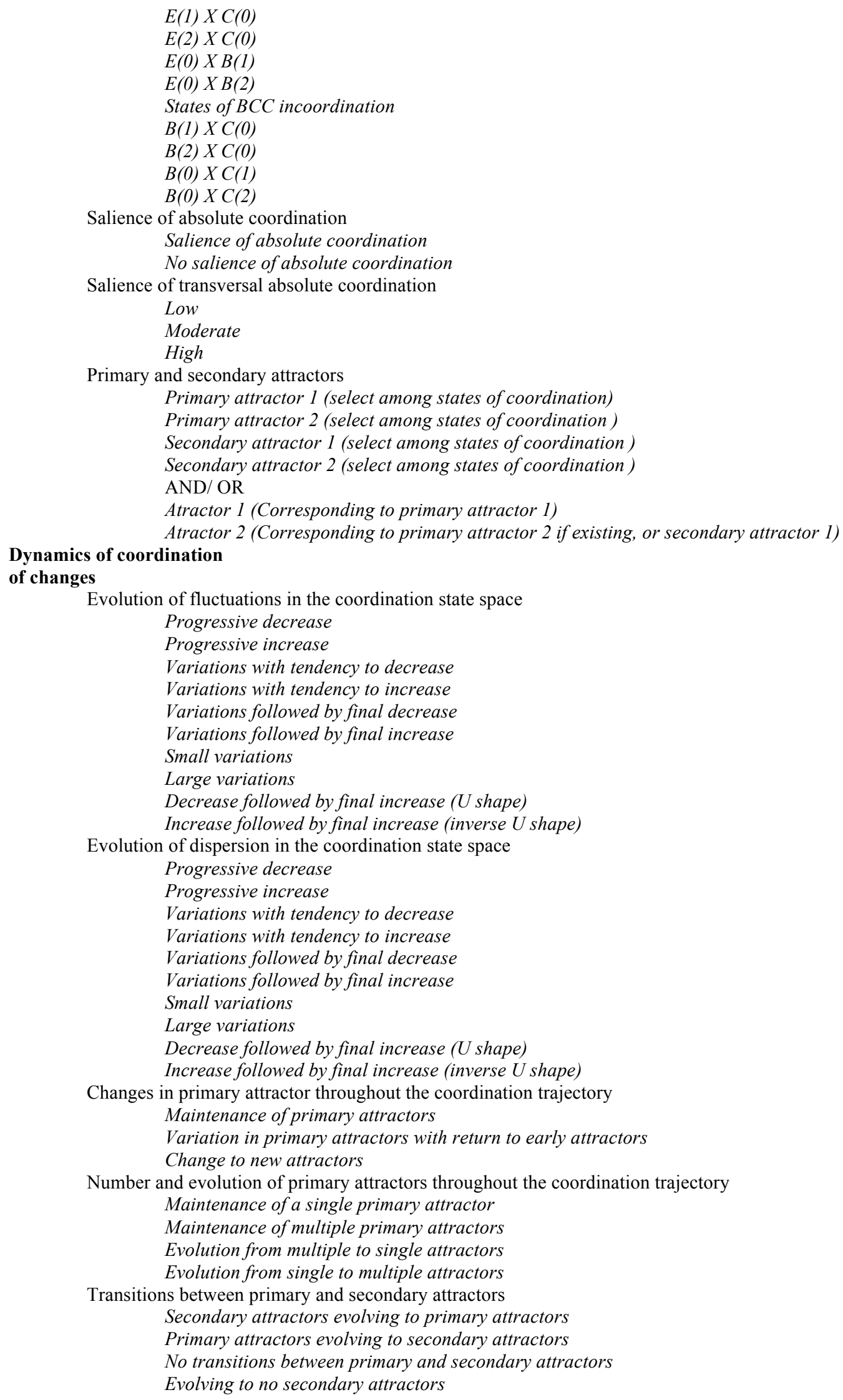

Number and evolution of primary attractors throughout the coordination trajectory Maintenance of a single primary attractor Maintenance of multiple primary attractors Evolution from multiple to single attractors Evolution from single to multiple attractors

Transitions between primary and secondary attractors Secondary attractors evolving to primary attractors Primary attractors evolving to secondary attractors No transitions between primary and secondary attractors Evolving to no secondary attractors 
Transitions ending in primary attractors

Final coordination tendency

Absolute coordination at high levels

Absolute coordination at moderate levels

Absolute coordination at low levels

Relative coordination with $X$ (specify the change that occurs at high levels)

Incoordination with $X$ (specify the change that occurs at low levels)

Not applicable/ No identifiable tendency 